\title{
PENGEMBANGAN CERGAM FISIKA BERBASIS STEM UNTUK MENUMBUHKAN LITERASI SAINS PADA SISWA SMP
}

\author{
Siska, Abdurrahman, Undang Rosidin \\ Program Studi Pendidikan Fisika, Universitas Lampung. \\ Email: siska.151297@gmail.com
}

Diterima: 18 Agustus 2019 Disetujui: 29 Januari 2020

\begin{abstract}
Abstrak
Tujuan dari pendidikan sains, yaitu menyiapkan siswa agar memiliki kemampuan literasi sains yang baik. Salah satu pendekatan yang mampu menciptakan tenaga ahli yang profesional dan memiliki literasi sains yang baik adalah pendekatan Science, Technology, Engineering, and Matchematics (STEM). Tujuan dari penelitian ini adalah untuk mengetahui karakteristik, validitas, dan pendapat siswa terkait cerita bergambar (cergam) yang dikembangkan. Metode penelitian yang digunakan adalah Research and Development (R\&D), sedangkan prosedur pengembangan mengacu pada pengembangan media intruksional oleh Sadiman, Haryono, \& Rahardjito (2016). Peneliti mengelolah data menggunakan konversi skor penilaian oleh Sugiyono. Cergam dikemas dalam 5 episode dalam 90 halaman. Peneliti memperoleh rerata skor validasi sebesar 3,51 yang termasuk dalam klasifikasi sangat valid, menarik, mudah, dan bermanfaat.
\end{abstract}

Kata Kunci: : Cergam Fisika, STEM, Literasi Sains.

\begin{abstract}
Science education aims to prepare students to have good scientific literacy skills. One approach that is able to create professional experts and have good scientific literacy is the approach of Science, Technology, Engineering, and Mathematics (STEM). The purpose of this study was to determine the characteristics, validity, and student's opinion related to the pictorial story which is developed. The research method used was Research and Development $(R \& D)$, while the development procedure refers to instructional media development by Sadiman, Haryono, \& Rahardjito (2016). The researcher analyzed the data using the conversion score by Sugiyono. Pictorial story is packed in 5 episodes in 90 pages. The researcher obtained an average validation score of 3.51 which was included in the classification as very valid, interesting, easy, and useful.
\end{abstract}

Keywords: Physics Pictorial Story, STEM, Science Literacy.

\section{PENDAHULUAN}

Prospek perkembangan siswa yang lebih lanjut, yaitu menerapkan pendidikan sains yang diperoleh di sekolah dalam kehidupan sehari-hari

(Permanasari, 2016). Menurut Dewi,

Kaniawati, dan Suwarma (2018)

menyebutkan bahwa tujuan

pembelajaran IPA khususnya fisika, 
Siska., Abdurrahman., Rosidin. - Pengembangan Cergam Fisika ...

yaitu untuk memperhatikan fenomena alam semesta di sekitar dan menekankan pada pemberian pengalaman langsung yang dapat memperkuat ingatan siswa dalam mengingat suatu informasi.

Menurut

Sulistiyowati,

Abdurrahman, dan Jalmo (2018) rangsangan berpikir yang dilakukan secara berkala akan menumbuhkan literasi sains siswa yang baik. Bahan ajar yang monoton menyebabkan siswa kurang antusias dalam belajar, sehingga saat proses pembelajaran berlangsung siswa hanya mendengar dan menyimak saja. Pendekatan yang digunakan guru untuk menyampaikan isi pembelajaran tentu juga harus diperhatikan (Abdurrahman, 2015).

Selama ini proses belajar mengajar terutama pada pelajaran fisika hanya menghafalkan fakta, prinsip atau teori saja. Perlu dikembangkan penunjang pembelajaran IPA khususnya fisika, untuk menumbuhkan literasi sains siswa. Literasi sains adalah kemampuan dalam menggunakan pengetahuan sains untuk mengenali permasalahan yang ada. Mengenali permasalahan tersebut dengan cara mengidentifikasi masalah dan menarik kesimpulan berdasarkan fakta dan bukti-bukti.

Taufiq, Dewi, \& Widiyatmoko (2014) menyebutkan bahwa pembelajaran di kelas memerlukan sarana dan prasarana pendukung berupa alat bantu seperti bahan ajar atau media. Santoso (2014) menyatakan bahwa cara awal untuk memperkenalkan perpustakaan kepada siswa, yaitu dengan memberikan penugasan sebagai tindak lanjut dari materi yang telah dijelaskan. Widodo \& Jasmadi (2008) menyebutkan bahwa bahan ajar juga membantu siswa untuk memperoleh pengetahuan baru. Banyaknya buku cerita bergambar yang masuk ke Indonesia mempengaruhi pengetahuan pembaca (Soedarso, 2014). Menurut Hidayah, Sajidan, \& Sugiharto (2016) cergam merupakan salah satu bahan ajar yang didesain menyerupai modul pembelajaran yang dapat digunakan sebagai sumber belajar.

Pendapat tersebut didukung oleh hasil penelitian Nurhaida, Hayanto, Junaidi, \& Syah (2015) yang memaparkan bahwa hasil akhir uji coba buku cergam memperoleh nilai 
Siska., Abdurrahman., Rosidin. - Pengembangan Cergam Fisika ...

76\% sampai 86\%, dimana nilai literasi sains siswa. Pendekatan tersebut lebih tinggi dibanding buku STEM memberikan kesempatan formal biasa. Sheffield, Koul, kepada siswa untuk menganalisis dan Blackley, Fitriani, Rahmawati, dan Resek (2018) juga mengkaji pengalaman belajar 291 siswa kelas 5 dan 6 Sekolah Dasar pada empat sekolah di Jakarta Utara. Penelitian tersebut menggunakan pendekatan STEM dan melibatkan para siswa untuk menggunakan keterampilan dan pengetahuan mereka tentang teknologi dan sains.

Pembelajaran yang menggunakan pendekatan STEM dapat melatih siswa dalam menerapkan atau mengaplikasikan pengetahuan yang dimilikinya untuk mendesain dan menyusun sesuatu sebagai bentuk pemecahan masalah terkait lingkungan di sekitarnya dengan memanfaatkan teknologi. Ketepatan dalam memilih cara penyajian pembelajaran atau dengan kata lain ketepatan dalam memilih pendekatan pembelajaran sangat penting dan menjadi kunci keberhasilan dalam proses pembelajaran. Pendekatan STEM merupakan salah satu pendekatan yang sangat cocok digunakan untuk menumbuhkan memecahkan berbagai masalah yang sering dijumpai dalam kehidupan sehari-hari.

Rumusan masalah dalam penelitian ini, yaitu mencari tahu karakteristik, validitas, dan pendapat siswa terkait bahan ajar yang dikembangkan. Bahan ajar yang dikembangkan berupa buku cerita bergambar (cergam) yang menggunakan pendekaan STEM. Materi yang dimuat dalam cergam adalah Kalor dan Perpindahannya.

Cergam merupakan salah satu bahan ajar yang dapat dijadikan alternatif untuk meningkatkan ketertarikan siswa terhadap suatu pelajaran yang bersangkutan. Cergam memuat rangkaian cerita yang terdiri dari tulisan yang didukung dengan gambar.

Berdasarkan penelitian pendahuluan diketahui bahwa kebutuhan guru dan siswa, serta angket wawancara. SMP Negeri 1 Natar membutuhkan bahan ajar berupa cergam sebagai sumber belajar dengan persentase siswa yang 
Siska., Abdurrahman., Rosidin. - Pengembangan Cergam Fisika ...

membutuhkan yaitu 85,29\%, kemenarikan, kemudahan, dan sedangkan persentase guru mata kemanfaatan cergam fisika berbasis pelajaran IPA sebesar $100 \%$. Hasil STEM pada materi Kalor dan penyebaran angket dan wawancara Perpindahannya, mendeskripsikan tersebut didapati bahwa masih belum pendapat siswa terhadap cergam banyak bahan ajar berupa cergam fisika berbasis STEM untuk sebagai sumber belajar yang menumbuhkan literasi sains. Peneliti digunakan guru di sekolah khususnya menggunakan metode Research and pelajaran fisika.

Development (R\&D). Desain penelitian yang digunakan seperti METODE

Penelitian ini bertujuan untuk merupakan desain hasil modifikasi mendeskripsikan karakteristik cergam proses pengembangan media fisika berbasis STEM pada materi instruksional oleh Sadiman, Haryono, Kalor dan Perpindahannya, \& Rahardjito (2009). mendeskripsikan validitas,

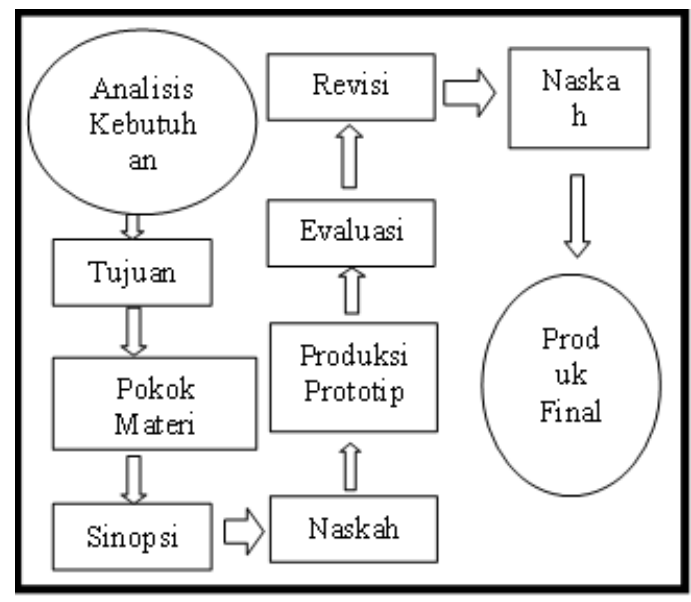

Gambar 1. Proses Pengembangan Media Intruksional

Model pengembangan media pokok materi, menyusun sinopsis, instruksional tersebut meliputi 10 membuat naskah awal, memproduksi prosedur, yaitu: analisis kebutuhan, prototipe, evaluasi, revisi, membuat merumuskan tujuan, mengembangkan naskah akhir, dan produk final. Model 
Siska., Abdurrahman., Rosidin. - Pengembangan Cergam Fisika ...

ini dipilih karena langkah-langkah pengembangannya lengkap dan sesuai dengan garis besar penelitian pengembangan media pendidikan, yaitu penelitian yang menghasilkan atau mengembangkan produk tertentu sesuai dengan standar isi kurikulum 2013.

Subjek penelitian dalam pengembangan produk ini, yaitu uji ahli bidang isi/materi dilakukan oleh 2 dosen Pendidikan Fisika dan guru IPA SMP Negeri 1 Natar. Uji ahli desain, yaitu dilakukan oleh 2 dosen Pendidikan Fisika dan guru IPA SMP Negeri 1 Natar. Uji satu lawan satu, yaitu diambil sampel penelitian 5 orang siswa di SMP Negeri 1 Natar.

Teknik pengumpulan data yang digunakan, yaitu metode angket dan wawancara. Kedua metode tersebut digunakan saat penelitihan pendahuluan untuk melihat tingkat kebutuhan produk yang akan dikembang. Metode tersebut juga digunakan untuk mengetahui tingkat validitas dan pendapat siswa terhadap cergam yang dikembangkan oleh peneliti. Data hasil analisis kebutuhan yang diperoleh dari guru dan siswa melalui penyebaran angket digunakan untuk menyusun latar belakang dan mengetahui tingkat kebutuhan terkait produk yang dikembangkan. Data hasil identifikasi kebutuhan ini kemudian digunakan untuk menentukan spesifikasi produk yang mungkin dikembangkan.

Data kesesuaian desain dan materi pembelajaran pada produk diperoleh dari ahli materi dan ahli desain melalui uji ahli/validasi ahli produk. Data kesesuaian tersebut digunakan untuk mengetahui tingkat kelayakan produk yang dihasilkan. Analisis data berdasarkan instrumen uji ahli, dan uji satu lawan satu dilakukan untuk menilai kesesuaian produk yang dihasilkan sebagai suplemen pembelajaran.

Uji validitas dan uji kepraktisan produk dikatakan valid jika memenuhi dua unsur kevalidan, yaitu valid berdsarkan teori dan valid berdasarkan kondisi di lapangan. Uji ahli atau instrumen uji validitas yang di dalamnya memuat data kesesuaian isi dan konstruk yang dikembangkan, digunakan untuk mengetahui tingkat kelayakan dan mengevaluasi kelengkapan materi pada cergam yang dikembangkan. Instrumen uji 
Siska., Abdurrahman., Rosidin. - Pengembangan Cergam Fisika ...

validitas memiliki empat pilihan uji validitas dan uji 1 lawan 1 jawaban sesuai konten pertanyaan, dilakukan dari jumlah skor yang dan masing-masing pilihan jawaban diperoleh, kemudian dibagi dengan mengartikan kelayakan instrumen, jumlah total skor tertinggi dan yaitu: "sangat layak", "layak", hasilnya dikali dengan banyaknya "kurang layak", dan "tidak layak". pilihan jawaban. Instrumen yang dengan konten pertanyaan, yaitu: "1", digunakan memiliki empat pilihan “2”, “3”, dan "4" di mana jawaban jawaban, sehingga skor penilaian total "1" berati "Tidak Valid", "2" berarti "Kurang Valid", "3" berarti "Valid", "4" berarti "Sangat Valid". Instrumen uji 1-1 yang melibatkan lima orang siswa SMP Negeri 1 Natar, Lampung Selatan, Lampung.

Angket Uji 1 lawan 1 memiliki 4 pilihan jawaban sesuai dengan konten pertanyaan. Uji ini dilakukan untuk mengetahui tingkat kemenarikan, kemudahan, dan kemanfaatan cergam dapat dicari dengan menggunakan rumus:

Skor Penilaian $=\frac{\text { Jumlah skor pada instrumen }}{\text { Jumlah nilai total skor tertinggi }} \times 4$

Data yang diperoleh dari hasil validasi ahli, akan diketahui tingkat kelayakannya berdasarkan skor yang ditampilkan pada Tabel 1.

Hasil dari skor penilaian tersebut kemudian dicari rata-ratanya dan selanjutnya dikonversikan ke pernyataan kualitas.

yang telah dibuat. Penilaian instrumen

Tabel 1. Konversi Skor Penilaian Menjadi Pernyataan Nilai Kualitas

\begin{tabular}{ccl}
\hline $\begin{array}{c}\text { Skor } \\
\text { Penilaian }\end{array}$ & $\begin{array}{c}\text { Rerata } \\
\text { Skor }\end{array}$ & \multicolumn{1}{c}{ Klasifikasi } \\
\hline 4 & $3,26-4,00$ & Sangat valid/Menarik/Mudah/Bermanfaat \\
3 & $2,51-3,25$ & Valid/Menarik/Mudah/Bermanfaat \\
2 & $1,76-2,50$ & Kurang Valid/Menarik/Mudah/Bermanfaat \\
1 & $1,01-1,75$ & Tidak Valid/Menarik/Mudah/Bermanfaat \\
\hline
\end{tabular}

Sumber: Sugiyono (2016).

\section{HASIL DAN PEMBAHASAN}

Proses pembelajaran tidak lagi terikat pada kelas-kelas tradisional yang sangat dibatasi ruang dan waktu. Pendidikan berbasis teknologi telah mengatasi dan melampaui batasan- 
Siska., Abdurrahman., Rosidin. - Pengembangan Cergam Fisika ...

batasan tersebut. Revolusi tersebut memicu lahirnya inovasi pendidikan artinya pendidikan dan proses pembelajaran menjadi berbeda dibandingkan dengan masa lalu (Putra, 2011).

Materi dalam cergam disajikan secara menarik dan berisikan gambar yang menjelaskan dan memaparkan materi Kalor dan Perpindahannya. Materi ini disusun berdasarkan Kompetensi Inti (KI), Kompetensi Dasar (KD), indikator pembelajaran, dan tujuan pembelajaran yang disesuaikan dengan Kurikulum 2013 (K13) revisi. Materi Kalor dan Perpindahannya disajikan meliputi pengertian energi, sumber energi, bentuk energi dan perubahannya, pengertian kalor, macam-macam perpindahan kalor, pengaruh kalor terhadap perubahan suhu dan wujud benda/zat, dan rekayasa sains dari konsep perpindahan kalor.

Proses produksi prototype melalui beberapa tahapan. Tahap pertama, yaitu membuat lay out atau panel yang digunakan sebagai pola dasar atau sketsa gambar. Tahap kedua, yaitu membentuk sketsa atau gambaran dasar di dalam lay out yang akan menceritakan isi cerita. Peneliti menggunakan aplikasi Adobe Photoshop CS6 untuk membuat ilustrasi/gambar yang dimuat dalam cergam. Tahap ketiga, yaitu pewarnaan ilustrasi gambar. Tahap ini merupakan tahapan yang akan membuat gambar menjadi lebih hidup dan menarik dengan perpaduan warna yang membuat gambar tersebut seakan nyata. Tahap keempat, yaitu pemberian balon-balon teks. Gambar diberikan balon-balon teks, dimana balon-balon teks ini berfungsi sebagai tempat diletakkannya tulisan-tulisan yang berisikan informasi yang disampaikan oleh gambar.

Karakteristik cergam yang menyenangkan berpotensi memicu siswa untuk belajar secara mandiri. Mereka tidak akan bosan membaca cergam secara berulang-ulang. Siswa lebih mudah menangkap materi pelajaran yang disampaikan. Cergam yang dikembangkan ini mempunyai karakteristik, yaitu cergam dikemas dalam 5 episode dalam 90 halaman yang memaparkan materi Kalor dan Perpindahannya. Cergam ini juga memuat latihan soal dan petualangan tokoh. Selain itu, ilustrasi gambar dan 
Siska., Abdurrahman., Rosidin. - Pengembangan Cergam Fisika ...

percakapan yang digunakan dalam cergam mudah dipahami dan sesuai dengan fakta kehidupan sehari-hari. Cerita dan pesan yang disampaikan lewat gambar ditampilkan ke dalam bentuk panel-panel. Cergam yang dihasilkan dari penelitian pengembangan ini berisi materi Kalor dan Perpindahannya yang dikemas dalam bentuk cerita dan gambar dalam bentuk buku full colour. Produk yang telah dibuat selanjutnya diuji kelayakan/kevalidannya melalui uji internal lalu dievaluasi. Hasil pengembangan dapat dilihat pada gambar 2.

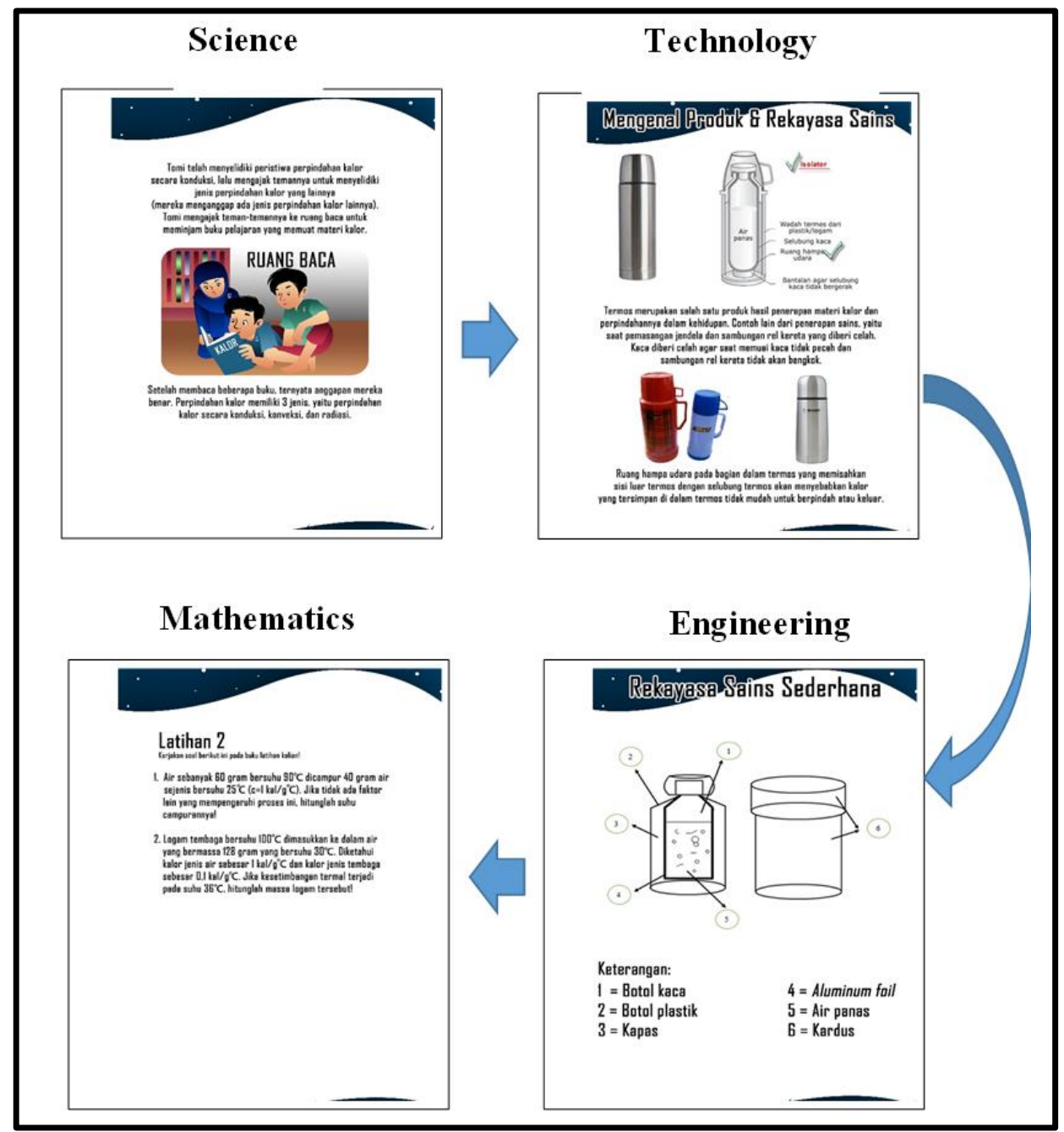

Gambar 2. Hasil Pengembangan Cergam berbasis STEM 
Siska., Abdurrahman., Rosidin. - Pengembangan Cergam Fisika ...

Uji materi dilakukan oleh dua ahli materi dari produk ini dapat orang dosen Pendidikan Fisika, serta dilihat pada Tabel 2. satu orang guru IPA SMP. Hasil uji

Tabel 2. Hasil Uji Ahli Materi

\begin{tabular}{cll}
\hline No. & \multicolumn{1}{c}{ Aspek Penilaian } & \multicolumn{1}{c}{ Saran Perbaikan } \\
\hline 1. & Komponen kelayakan & Perbaiki penyajian materi agar disesuaikan \\
& isi & dengan KI, KD, dan tujuan pembelajaran \\
2. & Komponen kebahasaan & Perbaiki percakapan dalam balon-balon teks \\
3. & Komponen penyajian & Perbaiki cara penulisan dan tata letak kalimat \\
\hline
\end{tabular}

Peneliti melakukan perbaikan desain dari produk ini dapat dilihat sesuai dengan saran perbaikan dari pada Tabel 3 .

penguji ahli. Nilai akhir yang

Peneliti melakukan perbaikan diperoleh pengembang dari penguji 1 sesuai dengan saran perbaikan dari sebesar 3,40, nilai dari penguji 2 penguji ahli. Nilai akhir yang sebesar 3,80, dan nilai dari penguji 3 diperoleh pengembang dari penguji 1 sebesar 3,20. Nilai akhir rata-rata dari ketiga penguji, yaitu sebesar 3,46. sebesar 3,40, nilai dari penguji 2 sebesar 3,86, dan nilai dari penguji 3

Uji desain dilakukan oleh dua sebesar 3,60. Nilai akhir rata-rata dari orang dosen Pendidikan Fisika, serta ketiga penguji, yaitu sebesar 3,62. satu orang guru SMP Hasil uji ahli

Tabel 3. Hasil Uji Ahli Desain

\begin{tabular}{|c|c|c|}
\hline No. & Aspek Penilaian & Saran Perbaikan \\
\hline & Penggunaan huruf & $\begin{array}{l}\text { Perbaiki ukuran huruf, jenis hurufnya yang } \\
\text { digunakan }\end{array}$ \\
\hline 2. & Komponen penyajian & $\begin{array}{l}\text { Perbaiki warna gambar agar kontras dengan } \\
\text { backgroud. } \\
\text { Perbaiki gambar agar sesuai dengan konsep } \\
\text { Kalor dan Perpindahannya. } \\
\text { Tambahkan balon teks untuk memudahkan } \\
\text { pembaca memahami percakapan tokoh. }\end{array}$ \\
\hline
\end{tabular}


Siska., Abdurrahman., Rosidin. - Pengembangan Cergam Fisika ...

Uji eksternal satu lawan satu yang dikembangkan, selanjutnya dilakukan dengan memilih secara pengembang memberikan kesempatan acak lima orang siswa kelas VII SMP kepada siswa untuk melihat langsung Negeri 1 Natar, Lampung Selatan, produk tersebut dengan cara Lampung. Pengembang memberikan membaca dan memahami cergam. pengarahan dan pengenalan terlebih Hasil analisis angket uji satu lawan dahulu kepada siswa terkait produk satu dapat dilihat pada Tabel 4.

Tabel 4. Hasil Uji Satu Lawan Satu

\begin{tabular}{ccl}
\hline No. & Aspek Penilaian & \multicolumn{1}{c}{ Komentar } \\
\hline 1. & Kemenarikan bahan ajar & $\begin{array}{l}\text { Cergam menarik untuk dipelajari karena } \\
\text { materi pelajaran disajikan dalam bentuk } \\
\text { tampilan gambar, warna dan jalur cerita } \\
\text { Cergam mudah dipelajari karena ilustrasi } \\
\text { gambar yang mewakili konsep pelajaran dan } \\
\text { mudah dijumpai dalam kehidupan sehari-hari } \\
\text { 2. }\end{array}$ Kemudahan bahan ajar \\
3. Kemanfaatan bahan ajar & $\begin{array}{l}\text { Cergambuat antuasias dalam } \\
\text { mempelajari materi pelajaran }\end{array}$ \\
\hline
\end{tabular}

Peneliti melakukan perbaikan total nilai akhir yang diperoleh komentar dari lima siswa yang telah pengembang dari ketiga uji tersebut membaca dan memahami isi cergam adalah sebesar 3,51. Berdasarkan Nilai akhir yang diperoleh konversi skor dari Sugiyono pada pengembang dari siswa ke-1 sebesar tahun 2016, skor sebesar 3,51 tersebut 3,20, nilai dari siswa ke-2 sebesar berada pada rentang skor 3,26-4,00, 3,63, nilai dari siswa ke-3 sebesar sehingga termasuk klasifikasi sangat 3,20, nilai dari siswa ke-4 sebesar valid, menarik, mudah, dan 3,66 , dan nilai dari siswa ke-5 sebesar 3,63. Nilai akhir rata-rata dari kelima siswa, yaitu sebesar 3,46.

Rata-rata nilai akhir yang diperoleh, yaitu uji ahli materi sebesar 3,46, uji ahli desain sebesar 3,62, dan uji satu lawan satu sebesar 3,46, maka bermanfaat.

$\begin{array}{rrr}\text { Peneliti juga } & \text { melakukan } \\ \text { wawancara untuk mengetahui }\end{array}$
pendapat siswa terkait cergam yang dikembangkan. Peneliti menggunakan sampel tiga siswa SMP Negeri 1 Natar, Lampung Selatan, Lampung. 
Siska., Abdurrahman., Rosidin. - Pengembangan Cergam Fisika ...

Sampel yang digunakan siswa kelas VII yang telah mempelajari materi Kalor dan Perpindahannya yang dipilih secara acak.

Rata-rata siswa berpendapat bahwa cergam lebih menarik minat membaca. Satu sampel yang mengaku tidak gemar membaca, namun setelah melihat cara penyampaian materi kalor melalui cergam siswa tersebut penasaran dan ingin membaca berkelanjutan. Selain itu, siswa mengaku bahwa tiap episode yang dihadirkan di dalam cergam membuat siswa bersemangat dan tidak jenuh dalam belajar. Hal ini sesuai dengan penelitian yang dilakukan oleh Nurhaida et al. (2015) yang menyatakan bahwa buku cergam lebih efektif dan menarik minat belajar siswa dibanding buku formal biasa, yaitu $76 \%-86 \%$ lebih tinggi. Selain itu, hasil penelitian ini juga memperkuat penelitian yang telah dilakukan oleh

\section{KESIMPULAN DAN SARAN}

Kesimpulan

Cergam yang dikembangkan dikemas dalam 5 episode dalam 90 halaman yang memaparkan materi
Kalor dan Perpindahannya menggunakan pendekatan STEM. Cergam ini memuat latihan soal dan petualangan tokoh. Selain itu, ilustrasi gambar dan percakapan yang digunakan dalam cergam mudah dipahami dan sesuai dengan fakta kehidupan sehari-hari.

Total nilai akhir yang diperoleh dari ketiga uji tersebut adalah sebesar 3,51. Menurut konversi skor dari Sugiyono pada tahun 2016, skor sebesar 3,51 tersebut berada pada rentang skor 3,26 - 4,00, sehingga termasuk klasifikasi sangat valid, menarik, mudah, dan bermanfaat.

Cara penyampaian materi kalor melalui cergam membuat siswa penasaran dan ingin membaca berkelanjutan. Ilustrasi gambar dan fenomena yang dihadirkan dalam cergam, memudahkan siswa dalam mengingat materi yang disampaikan. Timbulnya minat membaca, meningkatnya ingatan, dan semangatnya siswa dalam belajar mampu mendorong tumbuhnya literasi sains siswa dengan baik.

Saran

Saran untuk guru, perhatikan secara seksama kondisi siswa baik 
Siska., Abdurrahman., Rosidin. - Pengembangan Cergam Fisika ...

internal ataupun eksternal agar materi yang akan disampaikan dapat tersampaikan secara merata kepada seluruh siswa.

Bagi siswa, sebaiknya dalam membaca cergam ini secara berurutan (sistematis) karena setiap panel saling berhubungan satu sama lain. Bagi siswa, bahan ajar berupa cergam ini dapat digunakan secara mandiri maupun kelompok. Bahan ajar berupa cergam ini dapat dikembangkan pada materi lain yang lebih luas.

\section{DAFTAR PUSTAKA}

Abdurrahman. 2015. Guru Sains sebagai Inovator; Merancang Pembelajaran Sains Inovatif Berbasis Riset. Bandarlampung: Media Akademi.

Dewi, M., Kaniawati, I., \& Suwarma, I., R. 2018. Penerapan Pembelajaran Menggunakan Fisika STEM untuk Meningkatkan Kemampuan Memecahkan Masalah Siswa pada Materi Listrik Dinamis. Seminar Nasional Quantum, 2477-1511.

Hidayah, E., N., Sajidan, \& Sugiharto, B. 2016. Penerapan Model Pembelajaran ClassWide Peer Tutoring (CWPT) disertai Media Cergam untuk Meningkatkan Kualitas Pembelajaran Biologi Siswa Kelas X \& SMA Negeri 2 Sukoharjo Tahun Pelajaran
2011/2012. Pendidikan Biologi, 4(2),98-108.

Permanasari, A. 2016. STEM Education: Inovasi dalam Pembelajaran Sains. Prosiding Seminar Nasional Pendidikan Sains (SNPS), 23-34.

Putra, N. 2011. Research \& Development. Jakarta: Raja Grafindo Persada.

Sadiman, A. S., Rahardjo, R., \& Haryono, A. Rahardjito. (2009).

Media Pendidikan, Pengertian,

Pengembangan, dan

Pemanfaatannya. Jakarta:

Rajawali.

Santoso, H. 2014. Membangun Minat

Baca Anak Usia Dini melalui

Penyediaan Buku Bergambar.

Artikel Pustakawan

Perpustakaan Universitas

Negeri Malang.

Sheffield, R. S., Koul, R., Blackley, S., Fitriani, E., Rahmawati, Y., \& Resek, D. (2018). Transnational examination of STEM education. International Journal of Innovation in Science and Mathematics Education (formerly CALlaborate International), 26(8)

Soedarso, N. 2014. Perancangan Buku Ilustrasi Perjalanan Mahapatih Gajah Mada. Humaniora, 5(2), 561-570.

Sugiyono. 2016. Metode Penelitian Pendidikan. Bandung: Alfabeta. Sulistiyowati, Abdurrahman, Jalmo, T. 2018. The Effect of STEMBased Worksheet on Students Science Literacy. Tadris: Jurnal Keguruan dan Ilmu Tarbiyah, 3(1): 89-96.

Taufiq, M., Dewi, N., R., \& Widiyatmoko, A. 2014. Pengembangan Media 
Siska., Abdurrahman., Rosidin. - Pengembangan Cergam Fisika ...

Pembelajaran IPA Terpadu

Berkarakter Peduli Lingkungan

Tema

Berpendekatan

Edutaintment.
"Konservasi"

Science-

Jurnal
Pendidikan IPA Indonesia, 3(2), 140-145.

Widodo, C., S. \& Jasmadi. 2008. Panduan Menyusun Bahan Ajar Berbasis Kompetensi. Jakarta: Kompas Gramedia. 